\title{
Convective Froude number and Byram's energy criterion of Australian experimental grassland fires
}

\author{
A.L. Sullivan * \\ Ensis: A Joint Venture of CSIRO and SCION, and Department of Theoretical Physics, \\ Research School of Physical Sciences and Engineering, \\ The Australian National University, \\ Canberra, ACT 0200, Australia
}

\begin{abstract}
A subset of experimental fires, conducted in the Northern Territory, Australia, in July and August 1986, was analysed to examine the role of the convective Froude number and Byram's energy criterion $\left(P_{\mathrm{w}} / P_{\mathrm{f}}\right)$ in the behaviour of grassland fires. Forms of these dimensionless numbers were obtained from the literature as were functions relating independent variables in these formulations to measured quantities. It was found that Byram's energy criterion is simply the inverse cube of the convective Froude number and thus, was not examined in detail. It was found that the convective Froude number is not reflected in the observed behaviour of fires, as previous authors have suggested, despite the range of experimental conditions (wind speed $1.5-7.5 \mathrm{~ms}^{-1}$, rate of spread $0.05-2.82 \mathrm{~ms}^{-1}$ ).

Crown Copyright (C) 2006 Published by Elsevier Inc. on behalf of The Combustion Institute. All rights reserved.
\end{abstract}

Keywords: Dimensionless analysis; Wildland fire behaviour; Prediction

\section{Introduction}

The behaviour of a wildland fire is determined by the interactions between gravity, the atmosphere, the earth's surface and the fire itself, of which the interaction between the fire and the atmosphere is the most involved [1]. Two methods of characterising this interaction were identified in the literature and examined using data obtained

\footnotetext{
* Fax: +61 261254676.

E-mail address: als105@rsphysse.anu.edu.au
}

from field experiments in order to explore simple predictors of fire behaviour.

The convective Froude number [2,3] (Eq. (1)), and Byram's energy criterion $[1,4,5]$, (Eq. (2)), are non-dimensional numbers that consider the interaction of the horizontal dynamic forces of the wind flow over the fire with the vertical buoyant forces of the fire.

The Clark convective Froude number $[2,3], F_{\mathrm{c}}$, is given by:

$$
F_{\mathrm{c}}=\sqrt{\frac{(u-r)^{2}}{g \frac{\Delta \theta}{\theta_{\mathrm{a}}} D}}
$$

1540-7489/\$ - see front matter Crown Copyright (C) 2006 Published by Elsevier Inc. on behalf of The Combustion Institute. All rights reserved. doi:10.1016/j.proci.2006.07.053 
where $u$ is the wind speed $\left(\mathrm{ms}^{-1}\right), r$ is the rate of forward spread of the fire $\left(\mathrm{ms}^{-1}\right), g$ is gravity $\left(9.8 \mathrm{~ms}^{-2}\right), \frac{\Delta \theta}{\theta_{\mathrm{a}}}$ is the convective buoyancy (the ratio of the difference between the ambient potential temperature, $\theta_{\mathrm{a}}$, and the potential temperature in the convection column $\theta_{\mathrm{c}}$ ), and $D$ is the flame depth, ${ }^{1}$ the depth of the flaming zone of the fire front.

Byram's energy criterion or convection number, $N_{\mathrm{c}}$, for neutrally stable, non-entraining atmosphere [4] is given by:

$N_{\mathrm{c}}=\frac{P_{\mathrm{f}}}{P_{\mathrm{w}}}=\frac{\frac{g I}{c_{\mathrm{p}} \theta_{\mathrm{a}}}}{\frac{\rho(u-r)^{3}}{2}}=\frac{2 g I}{\rho c_{\mathrm{p}} \theta_{\mathrm{a}}(u-r)^{3}}$,

where $I$ is fireline intensity $\left(\mathrm{kW} \mathrm{m}^{-1}\right), \rho$ is air density $\left(1.2 \mathrm{~kg} \mathrm{~m}^{-3}\right), c_{\mathrm{p}}$ is the specific heat of dry air at constant pressure $\left(1.005 \mathrm{~J} \mathrm{~kg}^{-1} \mathrm{~K}^{-1}\right), \theta_{\mathrm{a}}$ is the absolute ambient air temperature, ${ }^{2} u$ is mean wind speed $\left(\mathrm{ms}^{-1}\right)$ and $r$ is rate of forward spread of the fire $\left(\mathrm{ms}^{-1}\right)$. It should be noted that the ratio of forces in Byram's convection number is the reciprocal of those in the convective Froude number.

Byram [1] considered the ratio of these forces to be an indicator of the vertical structure of the convection over a fire and while not directly related to specific fire behaviour could be useful in understanding and predicting the onset of erratic fire behaviour, in which behaviour is inconsistent over short periods, and the occurrence of 'blowup' fires [4], in which a previously quiescent fire suddenly exhibits sustained extreme behaviour and rapid rates of spread. These situations present a great threat to firefighter safety.

When the forces are relatively equal $\left(N_{\mathrm{c}} \simeq F_{\mathrm{c}} \simeq 1\right)$, the fire behaviour would be erratic. In the initial stages of a fire, $N_{\mathrm{c}}$ would be less than unity but as the fire grows and its intensity increases, $N_{\mathrm{c}}$ would approach unity and surpass it. When the buoyant force far exceeds that of the inertial forces for some height above the fire (usually $300 \mathrm{~m}$ ), extreme fire behaviour and blow-up characteristics are likely to occur. Byram [1] defined four ways of describing this onset:

1. The fire changes from an essentially 2-dimensional to a 3-dimensional phenomenon.

2. The fire changes from a forced-convection type to a free-convection type.

3. The fire acquires a convection column, instead of maintaining a smoke plume.

4. The fire blows up.

\footnotetext{
${ }^{1}$ Clark et al. [2,3] described this as fire width but Clark (personal communication, 2005) admitted this was a misuse of terminology.

${ }^{2} \theta$ is related to environmental temperature $T$, through the relation $\theta=T\left(\frac{\rho}{\rho_{0}}\right)^{\gamma}$ where $\rho_{0}$ is the air density at some reference height, and $\gamma$ is the ratio of specific heat to gas constant. If comparing, as we are here, temperatures at the same height, then $\theta_{\mathrm{a}}=T$.
}

Clark et al. [3] proposed that the erratic behaviour of wildland fires (described as a 'blow-up') results from a bifurcation in $F_{c}^{2}$ space due to an extreme level of interaction between the atmospheric and fire dynamics. Numerical experiments to assess the utility of $F_{\mathrm{c}}^{2}$ in predicting fireline behaviour showed that fires with large $F_{c}^{2}$ values $\left(F_{\mathrm{c}}^{2}>1\right)$ had little interaction between the fire and atmosphere as the flow did not respond to the heating supplied by the fire. Such a fire is described as 'wind-driven'. When $F_{\mathrm{c}}^{2}<1$ the flow responded strongly to the heating supplied by the fire and the fire can be described as 'plume- or convection-driven' [6]. Clark et al. [3] suggests that this regime can possibly result in fire blowup conditions, in agreement with Byram.

The impact of either $N_{\mathrm{c}}$ or $F_{\mathrm{c}}$ on fire behaviour has not been tested or validated against field observations $[3,5]$. The opportunity was taken to study the role of $N_{\mathrm{c}}$ and $F_{\mathrm{c}}$ using a well-measured and well-documented set of field experiments conducted in grassland fuels. The data of Cheney et al. $[7,8]$ is a unique set of detailed fire behaviour observations and measurements and provides an unmatched glimpse into the phenomenon of large, unconstrained fires in grassland fuels - the simplest of wildland fuels.

\section{Experimental methodology}

\subsection{Field experiments}

In 1986, the Commonwealth Scientific and Industrial Research Organisation in Australia undertook a series of wildland fire experiments in the grass plains of the Northern Territory, Australia. The aim of these experiments was to investigate the importance of fuel characteristics on rate of forward spread of large unconstrained fires. One hundred and twenty one experimental fires were carried out on a flood plain that was flat in a range of fuel treatments under a variety of weather conditions $[7,9]$. These fires were predominantly lit from lines ranging in length from 30 to $175 \mathrm{~m}$, although there were also a number of point ignitions, and allowed to burn freely over a predetermined area delineated by bare-earth firebreaks (Fig. 1). An empirical model of rate of fire spread in grass pastures of different grazed state was constructed using statistical regression techniques [8].

During each experiment, a number of timestamped oblique aerial photographs were taken of the fire. Each photograph was rectified with respect to the surveyed corners of each plot and an isopleth map of the fire perimeter created. Behavioural characteristics of each spread interval such as rate of spread, flame depth, and headfire width was measured from the isopleth map. Fuel characteristics (height, load, etc.) were measured 

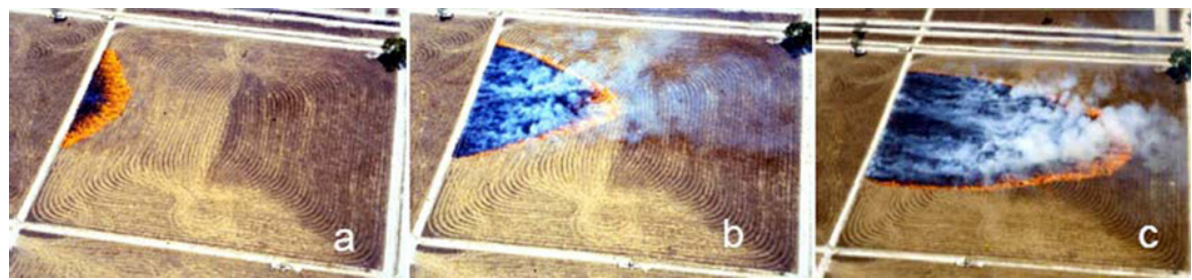

Fig. 1. Sequence of oblique aerial photographs of experimental fire C064, (a) $24 \mathrm{~s}$ after ignition, (b) $50 \mathrm{~s}$ after ignition, (c) $1 \mathrm{~m} 27 \mathrm{~s}$ after ignition. This fire was lit from a 50-m-long ignition line perpendicular to the prevailing wind on the upwind edge of a $100 \times 100 \mathrm{~m}$ plot. This plot was cut and removed Themeda australis grass (source: [15]).

on four transects through each plot approximately every $25 \mathrm{~m}$. A contour map was constructed and the representative fuel load affecting the fire spread for that interval selected (Fig. 2). The wind speed at a height of $2 \mathrm{~m}$ measured at the corners of each plot was averaged for each spread interval. On a number of experiments, balloon soundings of the upper atmosphere were carried out on the day of the fire [10], but no data were collected during fires.

\subsection{Experimental data}

A subset of the 121 experimental fires was chosen to investigate $F_{\mathrm{c}}$ and $N_{\mathrm{c}}$. This subset was selected by choosing those experimental fires with the maximum, minimum and mode of average

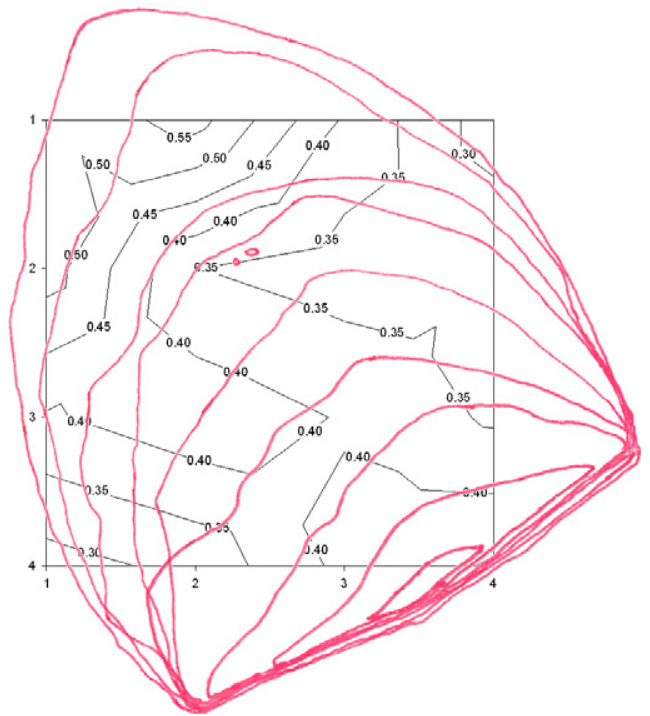

Fig. 2. Fuel load contour map $\left(\mathrm{kg} \mathrm{m}^{-2}\right)$ for plot $\mathrm{A} 023$ with fire isopleths overlaid. Representative fuel load and fuel height (giving bulk density) for each fire spread interval was selected. External box signifies extent of fuel sampling, not plot boundary. 2-m wind speed, rate of forward spread and effective ignition line length (the width of ignition perpendicular to the prevailing wind), resulting in nine fires. Table 1 gives a summary of some of the environmental and fire behaviour variables measured for these fires.

$N_{\text {c }}$ (Eq. (2)) contains only one variable, I, which was not measured but which is given by the simple relationship [11]:

$I=H r a$,

where $H$ is the heat yield of the fuel (Theme$\mathrm{da}=18067 \mathrm{~kJ} \mathrm{~kg}^{-1}, \quad$ Eriachne $=16951 \mathrm{~kJ} \mathrm{~kg}^{-1}$ ) [12], $r$ is the rate of forward spread and $a$ is the amount of available fuel per unit area $\left(\mathrm{kg} \mathrm{m}^{-2}\right)$. $I$ is in $\mathrm{kW} \mathrm{m}^{-1}$.

$F_{\mathrm{c}}$, however, posed considerably more challenge as convective buoyancy was not measured. Nelson [5], however, provides a relationship between $I$ and $\Delta \theta$ :

$I=\dot{m} c_{\mathrm{p}} \Delta \theta$,

where $\dot{m}$ is the mass flux rate $\left(\mathrm{kg} \mathrm{m}^{-1} \mathrm{~s}^{-1}\right)$ at the base of the convection column, but which was also not measured. This quantity can be calculated via the vertical velocity in the convection column, the dimension of the column and the density of the air:

$\dot{m}=\rho L \mathrm{w}$,

where $\rho$ is the density of air in the column $\left(\mathrm{kg} \mathrm{m}^{-3}\right)$, $L$ is a length scale of the convection column (m) and $\mathrm{w}$ is the updraft velocity $\left(\mathrm{ms}^{-1}\right)$.

Raupach [13] provides a relationship between $w$ and the buoyancy of a line fire assuming steady-state conditions:

$w=1.66 B^{1 / 3}$,

where $B$ is the buoyancy of a line fire $\left(\mathrm{m}^{3} \mathrm{~s}^{-3}\right)$ :

$B=\frac{g I}{\rho c_{\mathrm{p}} \theta}$.

The only unknown quantity in the above set of equations is $L$ in Eq. (5). It is not unreasonable, since we are considering the vertical plane through the fire and convection column, to set $L$ to the 
Table 1

A summary of some of the variables measured for the selected experimental fires

\begin{tabular}{lllllllllr}
\hline Fire ID & Fuel type & Fuel treat. & $\begin{array}{l}\text { Fuel load } \\
\left(\mathrm{kg} \mathrm{m}^{-2}\right)\end{array}$ & $\begin{array}{l}\text { Fuel ht } \\
(\mathrm{m})\end{array}$ & $\begin{array}{l}\text { Temp. } \\
\left({ }^{\circ} \mathrm{C}\right)\end{array}$ & $\begin{array}{l}\text { RH } \\
(\%)\end{array}$ & $\begin{array}{l}\text { Avg. WS } \\
\left(\mathrm{ms}^{-1}\right)\end{array}$ & $\begin{array}{l}\text { Eff. Ign. Len. } \\
(\mathrm{m})\end{array}$ & $\begin{array}{l}\text { ROS } \\
\left(\mathrm{ms}^{-1}\right)\end{array}$ \\
\hline A023 & Er & nat & 4.03 & 0.23 & 24 & 36 & 4.10 & 58 & 1.65 \\
A092 & Er & ret & 2.42 & 0.11 & 26.5 & 24 & 6.20 & 52 & 1.06 \\
B043 & Th & nat & 4.21 & 0.38 & 25 & 30 & 7.10 & 49 & 1.32 \\
B184 & Th & nat & 4.01 & 0.47 & 29 & 33 & 2.15 & 52 & 0.51 \\
B221 & Th & ret & 4.60 & 0.16 & 30 & 45 & 1.94 & 51 & 0.29 \\
B304 & Th & rem & 3.40 & 0.12 & 29 & 38 & 4.37 & 34 & 1.03 \\
C013 & Er & nat & 2.52 & 0.28 & 32 & 33 & 2.50 & 33 & 0.32 \\
F10 & Er & nat & 3.41 & 0.40 & 35.2 & 13 & 3.43 & 155 & 2.07 \\
F19 & Th & nat & 3.13 & 0.51 & 34 & 20 & 4.83 & 175 & 1.73 \\
\hline
\end{tabular}

Fuel type species: Er, Eriachne; Th, Themeda.

Treatments were: grass natural (nat), grass cut and clippings retained (ret), and grass cut and clippings removed (rem).

flame depth, $D$. Doing so results in an interesting, although not wholly unexpected, observation. Factorising Eq. (1) with Eqs. (3)-(7) gives:

$F_{\mathrm{c}}=1.29(u-r)\left(\frac{\rho c_{\mathrm{p}} \theta}{g I}\right)^{1 / 3}$.

Factorising and inverting Eq. (2) gives:

$\frac{1}{N_{\mathrm{c}}^{1 / 3}}=(u-r)\left(\frac{\rho c_{\mathrm{p}} \theta}{2 g I}\right)^{1 / 3}$.

Thus, $F_{\mathrm{c}} \propto \frac{1}{\left(N_{\mathrm{c}}\right)^{1 / 3}}$. Only the constants of Eqs. (8) and (9) differ, and even then, it is interesting to note that the cube-root of 2 is $\simeq 1.26$, suggesting that the factor of 2 in the denominator of Eq. (9) maybe misplaced. It is also interesting to note that Eq. (8) no longer has a length scaleits most attractive feature - as this was factored out by Eq. (5) and thus does not reflect the size or possible growth of the fire.

Due to this similarity between the two convective numbers, only the convective Froude number will be examined using the grassfire behaviour data.

\section{Results}

$F_{\mathrm{c}}$ was calculated for each fire spread interval, based on the average fuel load, wind speed, flame depth and rate of spread (ROS) for that interval. Figure 3 shows the rate of spread and calculated value for $F_{\mathrm{c}}$ for each interval of each experimental fire. The first and last intervals are highlighted by a thin or thick circle.

In three cases (A092, F10, and F19), ROS increases and $F_{\mathrm{c}}$ decreases with interval. B184, on the other hand, decreases ROS and increases $F_{\mathrm{c}}$ with interval. B043 and B304 initially increase ROS before it decreases. However, in the case of B043, $F_{\mathrm{c}}$ increases initially while in B304 it decreases before increasing in the final interval.

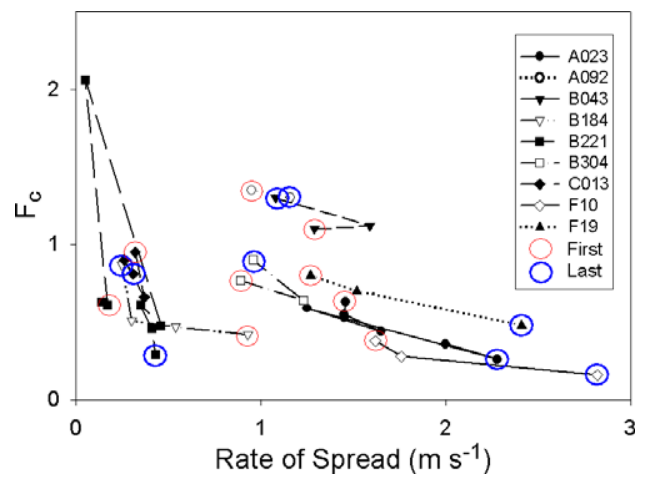

Fig. 3. Rate of spread and calculated convective Froude number for each interval of each experimental fire being considered. The first and last interval is noted by a thin or thick circle.

In the remaining cases (A023, B221, and C013), there is no readily discernible pattern to the evolution of ROS or $F_{\mathrm{c}}$.

No relationship between ROS and $F_{\mathrm{c}}$ with fuel species, treatment, load or height was found, in agreement with [7]. As a result, and because of the relatively small number of fires being considered, it was decided that the data should be grouped together for analysis, providing a total of 34 data points.

\section{Analysis and discussion}

There are two approaches to considering the utility of something like the convective Froude number in wildland fire situations: (1) can it be simply correlated with any normally observed environmental condition prior to the fire? and (2) can it be correlated with any normally observed fire behaviour during the fire? 
Table 2

Pearson correlation coefficients for prediction of $F_{\mathrm{c}}$ from a priori variables

\begin{tabular}{lllll}
\hline & $F_{\mathrm{c}}$ & Wind & Bulk density & FMC \\
\hline$F_{\mathrm{c}}$ & 1.00 & 0.37 & 0.48 & 0.06 \\
Wind & & 1.00 & 0.37 & 0.33 \\
Bulk density & & & 1.00 & 0.20 \\
FMC & & & & 1.00 \\
\hline
\end{tabular}

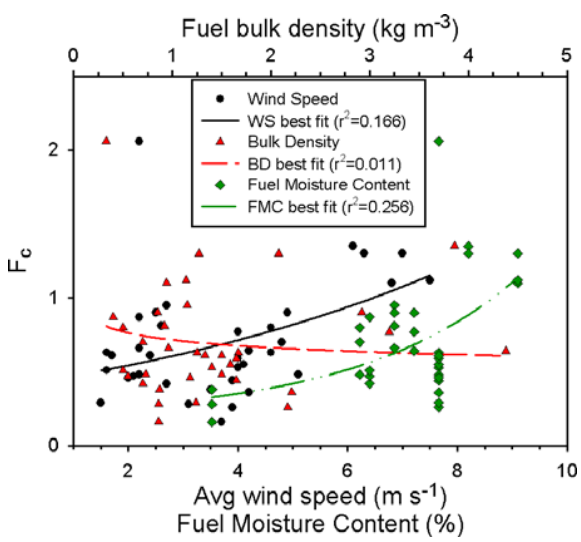

Fig. 4. Correlation between average wind speed, fuel bulk density and fuel moisture content (FMC) and the convective Froude number, $F_{\mathrm{c}}$. Lines of best fit with $r^{2}$ values are given to illustrate utility of variable to predict $F_{\mathrm{c}}$

\subsection{Correlating $F_{c}$ a priori}

In the first instance, comparisons of $F_{\mathrm{c}}$ were made with average $2-\mathrm{m}$ wind speed, the bulk density of the fuel and the fuel moisture content (FMC). Table 2 shows the linear Pearson correlation coefficients for these variables. In this analysis, fuel bulk density correlates best $\left(r^{2}=0.48\right)$ while FMC is worst $\left(r^{2}=0.06\right)$. Simple non-linear regression was then carried out. Figure 4 shows the correlations along with lines of best fit.

On the whole, none of the three variables measurable a priori correlate with $F_{\mathrm{c}}$ very well. As expected, there is a relationship with wind speed, however it is not very strong $\left(r^{2}=0.166\right)$. On the other hand, fuel moisture content has a much stronger relationship with $F_{\mathrm{c}}\left(r^{2}=0.255\right)$ which was not expected and improved upon its linear correlation with $F_{\text {c }}$.

Increasing wind speed and FMC result in an increase in the wind/buoyant force ratio, increasing $F_{\mathrm{c}}$. In the case of wind speed, this is a direct effect on the inertial force of the wind, however, in the case of FMC this an indirect effect on the energy released by the fire thus decreasing the buoyant force. This is affected mainly through energy lost evaporating the moisture prior to combustion. Increasing bulk density results in more fuel per unit volume and thus, greater energy released during combustion leading to higher buoyant force and thus, lower $F_{\mathrm{c}}$. It is interesting to note the effect of FMC is much greater than that of wind speed, even though wind is directly related to $F_{\mathrm{c}}$.

\subsection{Correlation of $F_{c}$ with fire behaviour}

In the second instance, $F_{\mathrm{c}}$ was compared to measurements of rate of forward spread, flame height and flame depth. Table 3 shows the linear Pearson correlation coefficients for these variables and two others with $F_{\mathrm{c}}$. As expected, ROS correlated best $\left(r^{2}=-0.37\right)$. Flame height correlated worst $\left(r^{2}=-0.16\right)$. Simple non-linear regressions were then carried out. Figure 5 shows the correlations along with lines of best fit.

As expected, rate of spread correlated best with $F_{\mathrm{c}}\left(r^{2}=0.314\right)$, but maybe not as well as would be expected. Flame height is not at all well correlated with $F_{\mathrm{c}}\left(r^{2}=0.039\right)$, flame depth only marginally better $\left(r^{2}=0.156\right)$. These variables are all tied closely to the buoyant component of the $F_{\mathrm{c}}$ through fuel combustion and thus vary inversely with $F_{\mathrm{c}}$.

\subsection{Other parameters}

\subsubsection{Time since ignition}

It appears from Fig. 3 that the majority of fires are still accelerating (i.e., ROS still increasing) when the last interval was recorded. Figure 6 plots $F_{\mathrm{c}}$ against the time since ignition as well as the width of the head fire for each interval. Lines of

Table 3

Pearson correlation coefficients for correlation of $F_{\mathrm{c}}$ with fire behaviour variables

\begin{tabular}{|c|c|c|c|c|c|c|}
\hline & $F_{\mathrm{c}}$ & ROS & Flame height & Flame depth & Headfire width & Time since ignition \\
\hline$F_{\mathrm{c}}$ & 1.00 & -0.37 & -0.16 & -0.37 & -0.33 & -0.16 \\
\hline ROS & & 1.00 & 0.47 & 0.66 & 0.59 & -0.48 \\
\hline Height & & & 1.00 & 0.49 & 0.16 & -0.24 \\
\hline Depth & & & & 1.00 & 0.21 & -0.43 \\
\hline Width & & & & & 1.00 & -0.03 \\
\hline Time & & & & & & 1.00 \\
\hline
\end{tabular}




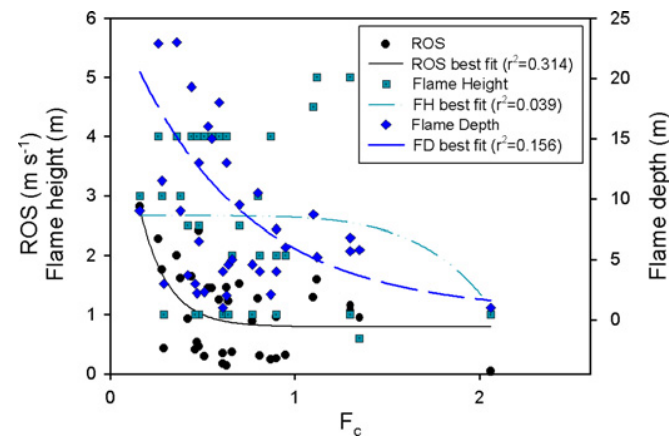

Fig. 5. Correlation between convective Froude number, $F_{\mathrm{c}}$, and rate of forward spread, flame height and flame depth. Lines of best fit with $r^{2}$ values are given to illustrate utility of $F_{\mathrm{c}}$ in predicting the fire behaviour variable.

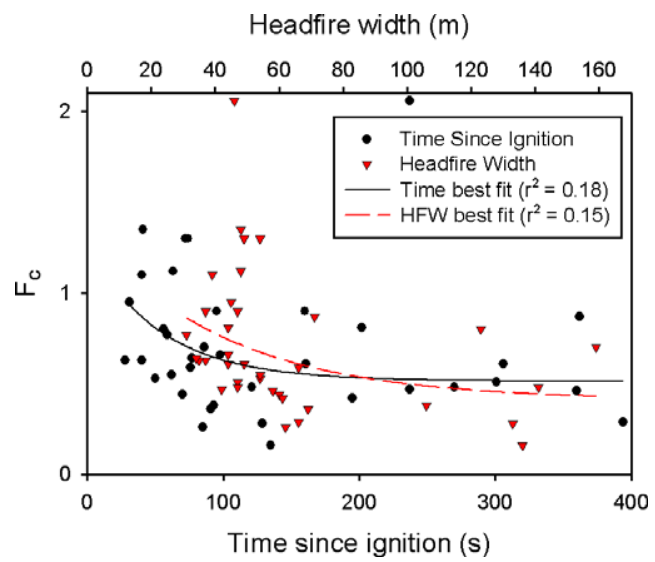

Fig. 6. Correlation between convective Froude number, $F_{\mathrm{c}}$, and time since ignition and headfire width. Lines of best fit with $r^{2}$ values are given to illustrate trends.

best fit (in which the outlier at $F_{\mathrm{c}}=2.06$ has been excluded) have been added. These lines do not show a strong relationship but illustrate a trend in the data.

Figure 6 shows that $F_{\mathrm{c}}$ decreases with increasing time up to about $200 \mathrm{~s}$. This suggests that during this period, the fires have not yet reached an equilibrium with the prevailing conditions. However, the slope of the trend line does flatten out after around $200 \mathrm{~s}$, indicating that it takes at least this long for fires to come into equilibrium with the prevailing conditions.

\subsubsection{Headfire width}

Headfire width is defined as the width of the fire front perpendicular to the prevailing wind that dominates the forward spread of the fire. Like time since ignition, $F_{\mathrm{c}}$ decreases with increasing headfire width (Fig. 6). This is interesting, since the lateral (perpendicular to the wind direction) dimension plays no part in the determination of the convective Froude number. It does support the proposition of Cheney et al. $[7,9,8]$ that the size of the fire affects the speed of the spread of the fire (wider fires generally spread faster than narrower fires). However, they also considered fire shape (pointed or parabolic) to play a part, which was not investigated here. It also suggests that fires that are more than $100 \mathrm{~m}$ wide are likely to reach equilibrium with the prevailing conditions sooner than narrower fires.

It is possible that the reverse behaviour of B184 and B043 (in comparison with A092, F10, and F19) is a result of these fires being too wide for the prevailing conditions and having to undertake a process of deceleration and size reduction in order to come into equilibrium with the wind field.

\subsection{Atmospheric stability}

As only three of the nine fires had atmospheric soundings conducted on the day of the experiment [10], this aspect was not investigated in any great detail. The temperature profiles for B184 and B221 (both conducted after the fires) show an adiabatic lapse rate (i.e., neutral stability) for the first $125 \mathrm{~m}$ and then a predominantly stable atmosphere up to $\simeq 1000 \mathrm{~m}$.

B043, by contrast shows a low level inversion to $450 \mathrm{~m}$, an adiabatic segment for the next $450 \mathrm{~m}$ and then a steep inversion beyond $900 \mathrm{~m}$. As [5] pointed out, Eq. (2) is for a neutrally stable atmosphere, and thus it might not be adequate for any other atmosphere, resulting in poor performance.

\subsection{Critical behaviour}

$F_{\mathrm{c}}$ and $N_{\mathrm{c}}$, while applicable at any height above a fire, are fundamentally driven by the output of the fire at the surface which defines the base value of the quantities, varied only by the vertical wind profile. Although no wind speed profiles above the fire were measured during experiments, the surface value calculated above is representative to a degree of $F_{\mathrm{c}}$ above each fire. Byram's statement that $N_{\mathrm{c}}$ be less than unity for some height above the fire in order for the fire behaviour to be critical implies that there must be a low level jet with wind speed profiles decreasing above the fire [14].

Only two fires (A092 and B043) have $F_{\mathrm{c}}$ values that remain above the critical threshold of unity for the life of the fire. The behaviour of these fires (average $\operatorname{ROS}=1.06$ and $1.32 \mathrm{~ms}^{-1}$, respectively, $I=4.4$ and $10.0 \mathrm{MW} \mathrm{m}^{-1}$ ) suggests fires that are not insignificant. However, the average wind speeds $\left(6.2\right.$ and $\left.7.1 \mathrm{~ms}^{-1}\right)$ are the highest of the subset and obviously greatly influenced the final 
$F_{\mathrm{c}}$ value. These fires did not behave differently from those fires whose $F_{\mathrm{c}}$ value was very much below unity.

The outlier point in all the graphs $\left(F_{c}=2.06\right)$ for fire B221, even though the average wind speed for the interval is $2.2 \mathrm{~ms}^{-1}$ (which is above the mean value for the life of the fire), reflects a quiescent period in the behaviour of the fire in which the ROS was $0.05 \mathrm{~ms}^{-1}$ and flame depth only $1 \mathrm{~m}$. This pause in behaviour could have been a result of a sustained lull in the wind speed affecting the fire that was not reflected in the average measured wind speed.

The lowest $F_{\mathrm{c}}$ value does correspond to the highest ROS value (fire F10) of $2.82 \mathrm{~ms}^{-1}$ in a wind speed of $3.7 \mathrm{~ms}^{-1}$. This fire has an average fireline intensity of $12 \mathrm{MW} \mathrm{m}^{-1}$ and thus is not greatly different to B043 discussed above.

All the fires produced easily observable smoke plumes, the angle of which depended on the wind, which could not be described as anything other than 3-dimensional. Since the behaviour of the fires in this dataset was not greatly observably different at $F_{\mathrm{c}}$ values above or below the critical value of unity, it appears that Byram's delineation of 2-dimensional and 3-dimensional fires and Clark's 'plume-driven' and 'wind-driven', are not appropriate. It is possible that the lifetime of the fires were too short to see this delineation.

\section{Conclusions}

A sub-set of nine experimental fires was selected from the complete dataset obtained by Cheney et al. $[7,8]$ and the role of the convective Froude number, $F_{\mathrm{c}}$ and Byram's convection number, $N_{\mathrm{c}}$, in the subsequent behaviour of the experimental fires investigated. In the process of seeking solutions for the convective Froude formulation that could use measured quantities, it was found that $N_{\mathrm{c}}$ is the inverse cube of $F_{\mathrm{c}}$ when the flame depth was used to define the vertical mass flux rate. As a result only $F_{\mathrm{c}}$ was subsequently examined in detail.

No simple useful relationship (linear or nonlinear) between individual quantities measurable before a fire such as average wind speed, fuel bulk density and fuel moisture content was found, although each had a trend with $F_{\mathrm{c}}$. More importantly, no significant relationship between $F_{\mathrm{c}}$ and observable fire behaviour parameters was found. Despite having a direct relationship with $F_{\text {c }}$, ROS only had a non-linear correlation coefficient of 0.314 with $F_{\mathrm{c}}$. Flame height and flame depth were poorly correlated with $F_{\mathrm{c}}$ (non-linear $r^{2}=0.039$ and 0.156 , respectively).

Time since ignition and headfire width were poorly correlated with $F_{\mathrm{c}}$. However, a definite trend is observable between these quantities. The former suggests that the fires were still accelerating and yet to obtain an equilibrium with the prevailing wind field. The latter supports the interaction between the rate of spread of the fire and its width perpendicular to the wind as proposed by Cheney et al. $[7,9,8]$.

This interaction between the size of the fire, the rate of spread and wind speed is one that the current formulation of the convective Froude number does not reflect. By considering only the 2-dimensional interaction of horizontal in the wind direction force with the vertical buoyancy force, the Froude number cannot include the size of the fire perpendicular to the wind flow. The importance of the headfire width in determining the rate of spread for the prevailing conditions suggests that there is a 3-dimensional spatial interaction involved in the behaviour of fires.

Both Clark et al. [2,3] (based on numerical experimentation using a coupled fire-atmosphere model implementing a quasi-empirical fire spread model) and Byram [4,5] (based on remote meterological weather observations and generalised descriptions of wildfire behaviour) suggested that $F_{\mathrm{c}}$ and $N_{\mathrm{c}}$ would provide an indication of the likely level of interaction between the atmosphere and the fire dynamics and thus the behaviour of the fire. Byram [1] suggested that the transition from a wind-dominated $N_{\mathrm{c}}$ to a fire-dominated $N_{\mathrm{c}}$ would indicate the transition from a $2 \mathrm{D}$ (i.e., plume-only) fire to a fully involved 3D (i.e., convection-driven) fire. No evidence of this was found in the subset of data investigated. In nearly all the fires, the convective Froude and convection numbers were immediately dominated by the fire dynamics with behaviour that, while of reasonable intensity, could not be described as extreme as would be expected from both Byram's and Clark et al.'s descriptions. This suggests that the descriptions of fires being 2D or 3D, 'wind-driven' or 'plume-driven', are purely academic and not of much utility in the field.

While more complicated multi-variable regressions might assist in improving the prediction of $F_{\mathrm{c}}$ a priori, the fact that there is no discernible relation between $F_{\mathrm{c}}$ and the resultant behaviour of the subset of fires argues against further investigation. It is possible that the fires are too short lived to exhibit the behaviour suggested by Byram and Clark et al., but Fig. 6 shows that the $F_{\mathrm{c}}$ asymptotes to a constant value suggesting the fires were reaching a psuedo-steady state for the prevailing conditions and would not change significantly while weather and fuel conditions remained stable.

\section{Acknowledgments}

I thank the CSIRO Centre for Complex Systems Science (John Finnigan and Rachel Williams) for supporting this project, Jim Gould for generously providing access to the data, Rowena Ball for insightful comments and Phil Cheney and Stuart Matthews for reviewing drafts. 


\section{References}

[1] G. Byram, in: K. Davis (Ed.), Forest Fire Control and Use, McGraw-Hill, New York, 1959, pp. 90-123.

[2] T.L. Clark, M.A. Jenkins, J. Coen, D. Packham, J. Appl. Meteorol. 35 (6) (1996) 875-901.

[3] T.L. Clark, M.A. Jenkins, J.L. Coen, D.R. Packham, Int. J. Wildland Fire 6 (4) (1996) 177-190.

[4] R. Nelson Jr., Int. J. Wildland Fire 3 (3) (1993) 131-138.

[5] R. Nelson Jr., Int. J. Wildland Fire 12 (1) (2003) $51-65$.

[6] M.A. Jenkins, T. Clark, J. Coen, in: E. Johnson, K. Miyanishi (Eds.), Forest Fires: Behaviour and Ecological Effects, 1st Ed., Academic Press, San Diego, CA, 2001, pp. 257-302.

[7] N. Cheney, J. Gould, W. Catchpole, Int. J. Wildland Fire 3 (1) (1993) 31-44.

\section{Comments}

Carlo Fernandez-Pello, U.C. Berkeley, USA. The air velocity in your experiments is relatively small, considering the scaling of $g$ and $u$ in either the Froude or Bryam numbers. I wonder if the results presented here can be considered as general.

Reply. While the air velocity values presented here are relatively small compared to the possible range that might occur during wildfires, the range is significant and, given that many workers in the field have found a near linear relationship between rate of forward spread of fires and wind speed, I would expect the results to be representative over a broader range.

Shankar Mahalingam, University of California, Riverside, USA. Have you considered correlating Froude number with suitable dimensionless quantities for fire height, rate of spread, etc.? In your presentation, it appears that you were seeking correlations between one dimensionless quantity and another dimensional quantity which might be problematic.

Reply. I have not considered correlating the Froude with suitable dimensionless quantities as you suggested but this is certainly an option for future work. I do not think there is anything inherently wrong with seeking correlations between dimensionless and dimensional quantities as one can correlate measurements of two-dimensional quantities without any problems. Also this is the most direct method that might be used by potential end-users.
[8] N. Cheney, J. Gould, W. Catchpole, Int. J. Wildland Fire 8 (1) (1998) 1-13.

[9] N. Cheney, J. Gould, Int. J. Wildland Fire 5 (1995) 237-247.

[10] A. Durre, T. Beer, Research Technical Paper 17, CSIRO Atmospheric Research, 1989.

[11] G. Byram, in: K. Davis (Ed.), Forest Fire Control and Use, McGraw-Hill, New York, 1959, pp. 61-89.

[12] D. Bowman, B. Wilson, J. Biogeography 15 (1988) 807-817.

[13] M. Raupach, Mathematical and Computer Modelling 13 (12) (1990) 113-121.

[14] G.M. Byram, Station Paper No. 35, USDA Forest Service Southeastern Forest Experiment Station, Asheville, North Carolina, April 1954.

[15] P. Cheney, A. Sullivan, Grassfires: Fuel, Weather and Fire Behaviour, CSIRO Publishing, Collingwood, Australia, 1997.

Reinhard Grabski, Institute of Fire Department, Germany. You found very small correlation coefficients. Is there a real correlation? Why have you chosen an exponential behavior for the fitting?

Reply. Yes, the correlations are small. In some cases, like bulk density or flame height, there is essentially no correlation at all, but in other cases, like fuel moisture content or rate of spread, the correlation is larger but just as tenuous. It may be argued that there is no real correlation for any of the measurable quantities and the convective Froude number, which is the point of the paper.

The nonlinear curve fitting was done by trial and error in order to achieve the best correlation coefficient, most of which are power-law or exponential fits.

Juan de Dios Rivera, Universidad Catolica de Chile, Chile. In studies made in Scotland, an important moisture gradient along the height of the grass has been found. Have you measured such a gradient?

Reply. The workers who undertook the field work for these experiments, Cheney et al. selected the fuel conditions for study primarily because the fuel moisture content of the grass was uniform in its distribution both vertically within the fuel strata and horizontally across the fuel bed - the fuel was fully cured and its moisture content only dependent upon atmospheric conditions, thus no such vertical gradient was measured. 